\title{
Study on the Organizational Pattern of Mental Lexicon for Chinese ESL College Students of Science
}

\author{
Wanyi $\mathrm{Du}^{1} \&$ Ying $\mathrm{Gao}^{1}$ \\ ${ }^{1}$ School of Software, Dalian University of Technology, Dalian, China \\ Correspondence: Wanyi Du, School of Software, Dalian University of Technology, Dalian, China. E-mail: \\ wendydudu@msn.com
}

Received: May 30, 2013 Accepted: June 14, 2013 Online Published: July 17, 2013

doi:10.5539/ijel.v3n4p50 URL: http://dx.doi.org/10.5539/ijel.v3n4p50

\begin{abstract}
This paper tries to provide both theoretical and pedagogical evidence on the organizational pattern of L2 mental lexicon for Chinese ESL learners and teachers. The evidence results from a carefully designed empirical research where the subjects are ESL students with different language proficiencies from software school of DUT. Results show that the organizational pattern of Chinese ESL learners' mental lexicon is a mix of semantic and non-semantic network, and it is rather dynamic. Efforts of reconstructing the lexicon network are necessary.
\end{abstract}

Keywords: mental lexicon, ESL learners, organizational pattern

\section{Introduction}

Through years of classroom teaching, many teachers of English noticed that poor word decoding ability is a major hindrance that would lead to slow reading speed, poor understanding, difficulty at listening comprehension and anxiety in oral practice, etc. Meanwhile, vocabulary acquisition at college level has been either overlooked in classroom practice or is carried out in inefficient manners. Then how to enlarge learner's vocabulary scale is now a major concern of both teachers and students. More and more researchers are focused on the field of vocabulary acquisition in recent years. Studies indicate that effective acquisition is closely related to the organization and work of human brains. Hence, the term of mental lexicon, which refers to the vocabulary stored in one's brain, causes increasing concern. The combination of psychology and language acquisition is not only a leading path to linguistic studies in the future but also makes pedagogical contributions to L2 teaching and learning.

The present research is designed to contribute both theoretically and pedagogically to the practice of mental lexicon in the field of Chinese ESL learners. Theoretically, this research will provide empirical evidence to the dispute over the organizational pattern of L2 mental lexicon for decades and have a discussion on the activation of learners' mental lexicon. Pedagogically, this research tries to demonstrate how lexicons are linked and retrieved in human brains, so that both learners and teachers could obtain initial knowledge about mental lexicon and contribute to the building of mental lexicon building according to ML Theories. Teachers and learners might also give a new thought on dispense of the time and effort in a more effective way both in and outside classroom.

\section{Literature Review}

\subsection{Definition of Mental Lexicon}

As a subfield of psycholinguistics, the study of mental lexicon originated in the late 1960s. By combining theories of linguistics and psychology, psycholinguists examine the mental processes of language acquisition, comprehension, and production. Mental lexicon is also called as subjective lexicon, internal lexicon, or mental dictionary.

Treisman (1960) first proposed the concept of mental lexicon in 1964. He defined that mental lexicon is the storage of all the information that a person has related to words of a language. According to him, in every speaker's mind there is a lexical representation which is a well organized system consisting of word's spelling, sound and meaning.

The study of mental lexicon has caused more and more concern within linguists, psychologists and anthropologists. Different definitions have been given by different researchers and scholars. J. C. Richards et al. 
(2000) gives the definition of mental lexicon as a mental system that contains all the information one knows about words which include pronunciation, patterns of grammar, and the meanings. According to Aitchison (1994), mental lexicon is also called mental dictionary, referring to the representation of words and their meanings stored permanently in one's memory. It is composed of two components: semantic-syntactic component is used to store word meaning and word class; phonetic-phonological component is used to store sound of a word.

\subsection{Organizational Pattern of L2 Mental Lexicon}

According to Aitchison, words in mental lexicon are neither organized in alphabetic order, nor like a disordered collection. Shown by the results of word association tests, words in mental lexicon are organized not only based on phonetic and spelling, but also on sense relationship. Based on empirical studies, many researchers agree that the organization of L1 mental lexicon is more semantically.

The study of L2 mental lexicon is not as much as that of L1 mental lexicon. And it still much relies on the result of L1 studies. Researchers of L2 mental lexicon hold different views over its organizational forms. There are mainly three different views: semantic, syntactic or phonological relations.

(1) Phonologically associated organization

Some researchers believe that the organization of L2 mental lexicon is basically different from L1 mental lexicon. It is more phonological because there are more phonological responses in word association tests than semantic responses. Paul Meara (1980) was the first one to claim that the L2 mental lexicon is mainly phonological while the organization of L1 mental lexicon is primarily semantically. In the Birkbeck Vocabulary Project in 1982, Meara drew the conclusion through the analysis of learners' responses during several word association tests that significant differences exist between L2 lexicon and that of native speakers. Listed below are features of L2 lexicon based on Meara's research project:

1) The word association responses of $\mathrm{L} 2$ learner are not as regular as native speaker and also the word types given are different;

2) The connections of words in L2 learners' mental lexicon are less stable than the connections of native speaker;

3) Phonological connections appear to play a much more important role in L2 mental lexicon than they do in the lexicon of native speaker; L2 learners show more frequent misunderstanding of the stimulus words and give unrelated associations;

4) Differences of the semantic links in words can be found between L2 learners and L1 mental lexicon.

Zhang Shujing (2004) came up with the conclusion after comparing the response patterns of 40 Chinese English learners with the responses of 19 native speakers that phonology plays a much more important role in the L2 mental lexicon than it does in the L1 mental lexicon. In her research, Chinese learners produced a total $36.9 \%$ of phonological responses even for familiar words, while native speakers only produced $2.2 \%$ phonological responses.

\section{(2) Semantically associated organization}

Singleton (1999) largely challenged the phonological view which has been widely accepted for decades through his publications based on his Modern Language Research Project (MLRP). By analyzing a series of data through C-test, WA test, Story telling and Translation, he argues that the organizational form of L2 mental lexicon is actually very similar to L1 mental lexicon.

Actually, some earlier studies also support the view of semantic organization. O'Gorman (1996) originally expected to find evidence supporting Meara's phonological view in a word association test of 22 Cantonese speakers, but later found her data tend to approve the opposite.

Soderman (1993) found a "shift in response types" in L2 mental lexicon. By testing four groups of ESL learners of different language proficiency levels, Soderman found a decrease in clang responses and syntagmatic responses with the increase of learners' proficiency level. Her findings also show a phonological-semantic shift in learners' associative patterns with the development of their lexical knowledge and language proficiency. The study suggested that the mental lexicon between L1 and L2 learners are not as different as it is believed earlier.

(3) Syntactic organization

Syntagmatic associates are words which collocate sequentially with the stimuli such as SELL-book, WHITE - snow. According to syntactic view, if large proportion of syntagmatic responses is produced in the WA test, then the L2 mental lexicon organization is syntactic. 
Wolter (2001) conducted a test by comparing the response types of 13 Japanese ESL speakers and 9 native speakers of English. The following numbers indicate the result: $19.7 \%$ of paradigmatic responses, $37.7 \%$ of syntagmatic responses, $35.1 \%$ of clang- other responses and $7.6 \%$ of no-responses. By comparison, it is also found that native speakers produced a higher proportion of paradigmatic responses while non-native speakers produced more syntagmatic responses. Therefore, Wolter concluded that syntagmatic connections is playing a significant role in L2 mental lexicon.

To summarize, none of the controversial sides could fully defend themselves. Those who hold the view of different organization between L1 and L2 mental lexicon could not deny the semantic associations in L2 lexicon organization. And those who believe that L2 lexicon resembles that of L1 also have to admit the continuous involvement of phonology and syntagmatic factors, even with those advanced L2 learners.

\section{Research Design}

\subsection{About the Subjects}

The subjects for the study came from four classes of first year students in the school of software, Dalian University of Technology. All the subjects are Chinese native speakers and have English as their foreign language. They are at the age of 18-21 and have been learning English for 6-12 years. Among the 96 subjects, only one has half month traveling experience in an English speaking country, which could be ignored since the short period of time might have little influence on his English proficiency. The numbers of male and female subjects are 77 and 19 respectively. All the subjects had received the same teaching syllabuses before coming to and in the university. In addition, all of the subjects had just taken the CET4.

Eight subjects - one female and seven male students were unfortunately excluded from the final study for the following reasons: (1) four of the subjects did not finish their VKS test. (2) Two of the subjects provided exactly the same answers to each of the tests. (3) Two of the subjects did not provide their scores of the reading test and CET 4, so it is impossible to determine their English reading proficiency. Thus the final valid number of subjects for the study was 88 .

The total subjects are divided into two groups according to their English proficiency calculated by their scores of CET 4. To make sure the two groups belong to two different language proficiency levels, an Independent Samples $t$ test was carried out by using SPSS 19.0, and the result is presented in following table 1, which indicates significant differences between the two groups of subjects.

Table 1. T-test results of VKS test of two groups of subjects

\begin{tabular}{rrrrrr}
\hline & group & $\mathrm{N}$ & Mean & Std. Deviation & Std. Error Mean \\
\hline \multirow{2}{*}{ score } & Low pro & 44 & 145.5909 & 11.17372 & 1.68450 \\
& High pro & 44 & 153.8409 & 8.26296 & 1.24569 \\
\hline
\end{tabular}

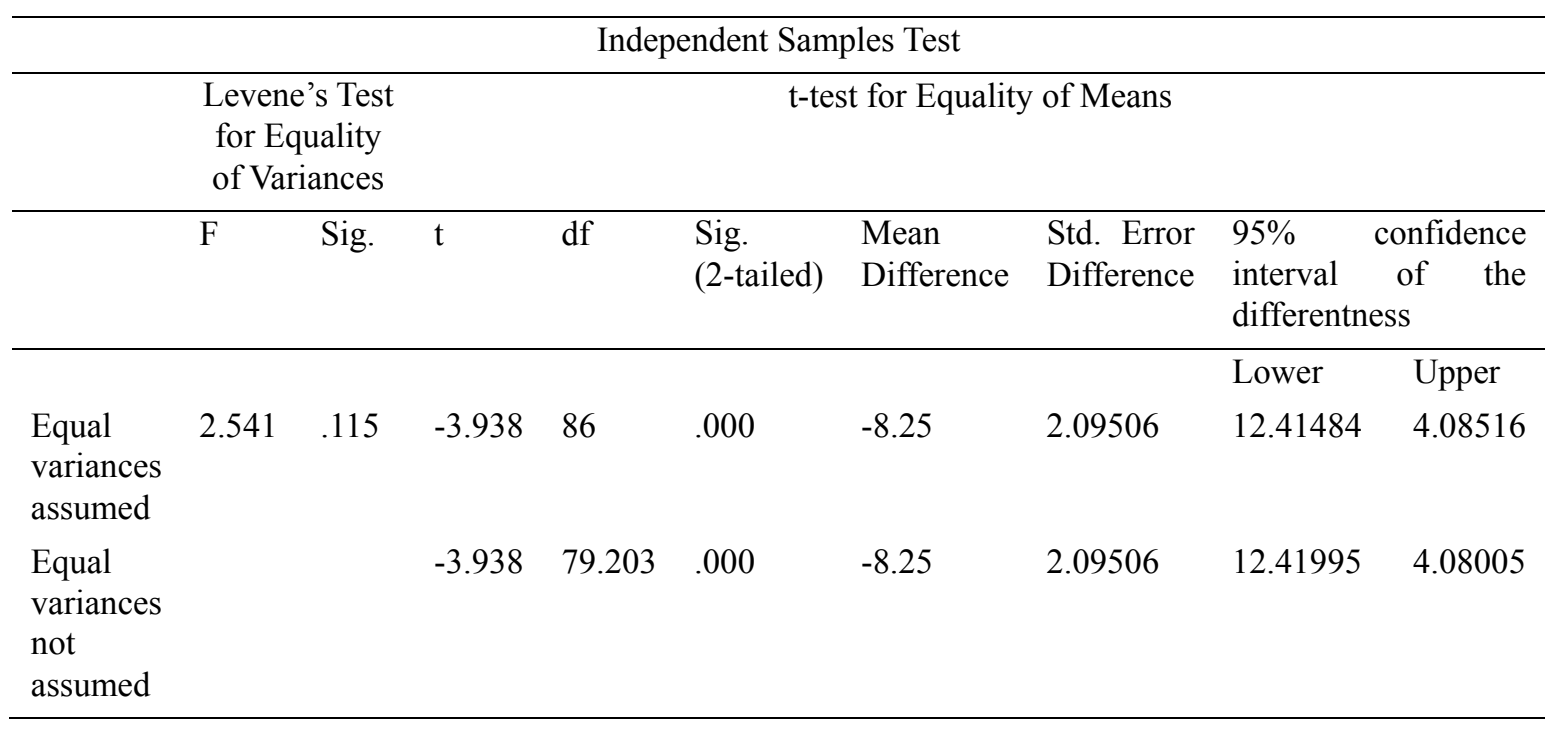




\subsection{Methods}

In linguistic study, especially in the study of mental lexicon, the WA test is one of the most reliable and widely used instruments. It has quite a long history. It is first developed by Sir Francis Galton and latterly refined. In any cases, word-association research has been prominent in work on the mental lexicon, including work on the L2 mental lexicon (Meara, 1982, 1984). A project focusing in part on lexical matters without a word-association test would probably have to face validity problem (Singleton, 1999). According to the purpose of the research, a free WA test which requires the subjects to give the first word coming into mind at the sight of the stimulus word will be adopted.

A vocabulary knowledge scale test (VKS test) of the stimulus words is designed to clarify the subjects' familiarity of the words. According to Wolter (2001), the scores of VKS test would be in accordance with the integration of a particular word into one's mental lexicon. This could also be used as a supplementary measurement to help the researcher explain different patterns of the subjects' response type. So it is essential to take the subjects' degree of familiarity with the stimulus words into consideration. The VKS test is designed to investigate the subjects' knowledge to each stimulus word on a three-point scale as follows:

\begin{tabular}{|ll|}
\hline I. & I don't remember having heard or seen the word before. \\
II. & I have seen or heard this word before, but I don't remember what it means. \\
III. & I know this word. It means___. (write a synonym or translation) \\
\hline
\end{tabular}

The word association test and the vocabulary knowledge scale test employed the same word list in the present research. 60 words were chosen from three word lists: The most frequent words from Brown Corpus; The most frequent word families from Academic English developed by Paul Nation; The Academic Word List by Paul Nation. The stimulus words were then divided as high frequency word group and low frequency word group. Each group consists of words with different grammatical classes as nouns, adjectives and verbs. Meanwhile, abstract and concrete words are equally distributed within each group. According to the scores of VKS test, an independent sample $t$ test was performed by SPSS 19.0. The following table 2 indicates that there is a significant difference between high frequency and low frequency groups of words selected.

Table 2. T-test results of VKS test between two groups of words

\begin{tabular}{rrrrrr}
\hline & group & $\mathrm{N}$ & Mean & Std. Deviation & Std. Error Mean \\
& & & & & \\
\hline score & High & 41 & 238.0732 & 32.62314 & 5.09488 \\
& Low & 19 & 179.1579 & 47.74034 & 10.95239 \\
\hline
\end{tabular}

\begin{tabular}{|c|c|c|c|c|c|c|c|c|c|}
\hline \multicolumn{10}{|c|}{ Independent Samples Test } \\
\hline & \multicolumn{2}{|c|}{$\begin{array}{l}\text { Levene's Test } \\
\text { for Equality of } \\
\text { Variances }\end{array}$} & \multicolumn{7}{|c|}{$\mathrm{t}$-test for Equality of Means } \\
\hline & \multirow[t]{2}{*}{$\mathrm{F}$} & \multirow[t]{2}{*}{ Sig. } & \multirow[t]{2}{*}{$\mathrm{t}$} & \multirow[t]{2}{*}{ df } & \multirow[t]{2}{*}{$\begin{array}{l}\text { Sig. } \\
\text { (2-tailed) }\end{array}$} & \multirow[t]{2}{*}{$\begin{array}{l}\text { Mean } \\
\text { Difference }\end{array}$} & \multirow[t]{2}{*}{$\begin{array}{l}\text { Std. Error } \\
\text { Difference }\end{array}$} & \multicolumn{2}{|c|}{$\begin{array}{l}95 \% \text { Confidence } \\
\text { interval of the } \\
\text { difference }\end{array}$} \\
\hline & & & & & & & & Lower & Upper \\
\hline $\begin{array}{l}\text { Equal } \\
\text { variances } \\
\text { assumed }\end{array}$ & 4.945 & .030 & 5.592 & 58 & .000 & 58.91528 & 10.53620 & 37.82479 & 80.00576 \\
\hline $\begin{array}{l}\text { Equal } \\
\text { variances } \\
\text { not } \\
\text { assumed }\end{array}$ & & & 4.877 & 26.084 & .000 & 58.91528 & 12.07943 & 34.08953 & 83.74102 \\
\hline
\end{tabular}




\subsection{Data Collection and Classification}

In this research, the WA test and VKS test were carried out in normal class hours. In order to avoid any pattern of recognition or memory effects, the WA test was done to the subjects before the VKS test. The tests were administered by teachers of the subjects in order to avoid any possible interfered effects brought by the researcher. It takes about forty minutes to finish both of the two tests and the questionnaire.

Since this is the first time for the subjects to participate in a WA test, the instructions were all given in their mother language, Chinese, with necessary explanation from the teachers. Before the test officially began, they were also given some time to write down their responses to four sampled stimulus words: GIRL, HOUSE, HAPPY, READ, so that to make sure they could understand fully what they were required to do in the test. The subjects were encouraged to write down the first word that comes to mind when they were at the sight of the stimulus words as quick as possible. They were also instructed to respond to each of the words from the list even when they were not familiar with the stimulus word at all. All the data were collected and classified for further analysis.

Since there is no universally accepted guideline for the classification of response words, it is always a big problem for any researcher to put each ambiguous response type into the right category. According to Jung (1918), "everyone who does practical work in association has found the classification of the results the hardest and most tedious part." Different classifications are adopted to satisfy researcher's different purposes. The aim of the present research is to identify the interactions between L2 readers' reading proficiency and the patterns of their mental lexicon organization. To focus on the links of words in the readers' mental lexicon, the responses of the WA test are classified as paradigmatic, syntagmatic, clang-other and no response. Such classifying model is on the basis of previous efforts of different researchers and present semantic theories.

\section{Data Analysis and Discussion}

After careful classification of the WA responses, Statistical Package for the Social Science software (SPSS, version 19.0) and Excel 2003 were used to calculate and analyze the data. Excel 2003 was used to perform quantitative analysis of the data, which include calculating the sum of whole data, the number of male and female subjects, the score of VKS test and WA test. Qualitative analysis was performed by using SPSS 19.0 to calculate descriptive statistics, including mean, standard deviation and independent-samples t-test to see whether there was any significant difference between high frequency and low frequency groups of stimulus words and the responses of high level and low level groups of subjects.

\subsection{The General Mental Lexicon Patterns of All the Subjects}

The results of general mental lexicon patterns of the research subjects are reported here. There is a comparison between the present research and previous study followed.

The first step of calculating response types is to identify each type of responses for each stimulus word. Then the total number of each type of responses was calculated by counting frequency in Excel 2003. Finally, the percentage of each type was calculated and the following Figure 1 was generated.

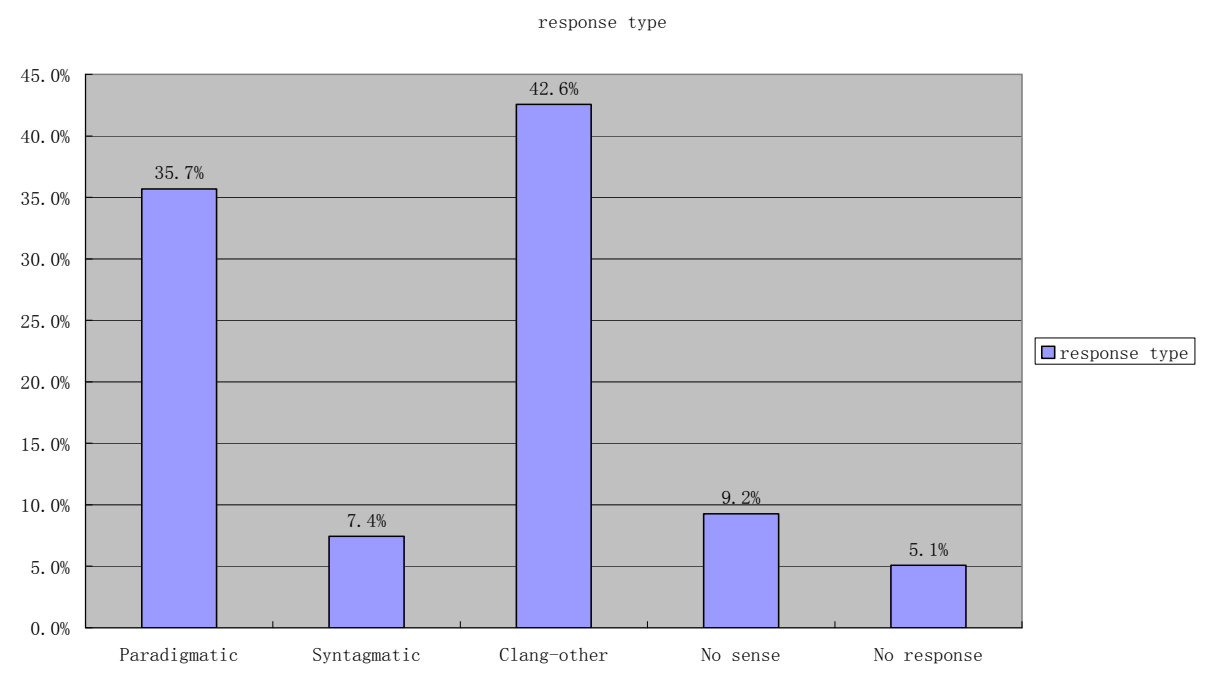

Figure 1. General mental lexicon patterns of all subjects 
As shown in Figure 1, L2 learners of English in this university produced a comparable proportion of responses in the word association task: $42.6 \%$ of clang-other responses, $35.7 \%$ of paradigmatic responses, $9.2 \%$ of no sense responses, $7.4 \%$ of syntagmatic responses and $5.1 \%$ of no responses. The result indicates that L2 learners of English produced a higher proportion of non semantic responses (the total of clang-other and no sense response is 51.8) than semantic responses (the total of paradigmatic and syntagmatic response is $43.1 \%$ ), which means that L2 learners generate lower proportion of meaningful responses. They rely a lot on meaningless non-semantic responses in word association test. At the same time, the major proportion of response type is clang-other and the second major proportion of response type is paradigmatic, which together occupy $78.3 \%$ of the total responses. Therefore, it might be reasonable to say that the overall response pattern of L2 learners is a mix of semantic and phonological associations.

From the results reported above, we can see that the finding of the present study is in accordance with Zhang Ping's view (2009). In her study, L2 learners of English produced much higher proportion of non semantic responses than native speakers of English but at the same time they still produce higher proportion of semantic responses than non semantic responses. The difference may lie in the choice of subjects where in Zhang's research all L2 learners came from university English major students who shall possess much higher language proficiency than subjects in present study who major in software at university.

Similar findings may also be conveyed in Wolter's (2001) and Zhang Shujing's (2004) studies. Wolter's comparison shows a significantly difference between native speakers and L2 English learners. In his study, L2 learners produced $57.4 \%$ of semantic responses and $35.1 \%$ of clang-other responses. Zhang Shujing provides approximately the same proportion of semantic and clang-other responses, although she supports Meara's phonological view of L2 mental lexicon. (shown in table 3)

Table 3. Zhang Shujing'sstatistics of response patterns (2004)

\begin{tabular}{ccc}
\hline Subjects & Native Speakers & L2 Learners \\
\hline No response & $1.9 \%$ & $2.3 \%$ \\
Non semantic & $19.6 \%$ & $49 \%$ \\
Semantic & $78.5 \%$ & $48.7 \%$ \\
\hline
\end{tabular}

\subsection{The General Mental Lexicon Patterns of High Level and Low Level Groups}

The comparison of response types between high level and low level groups is shown in the following Figure 2.

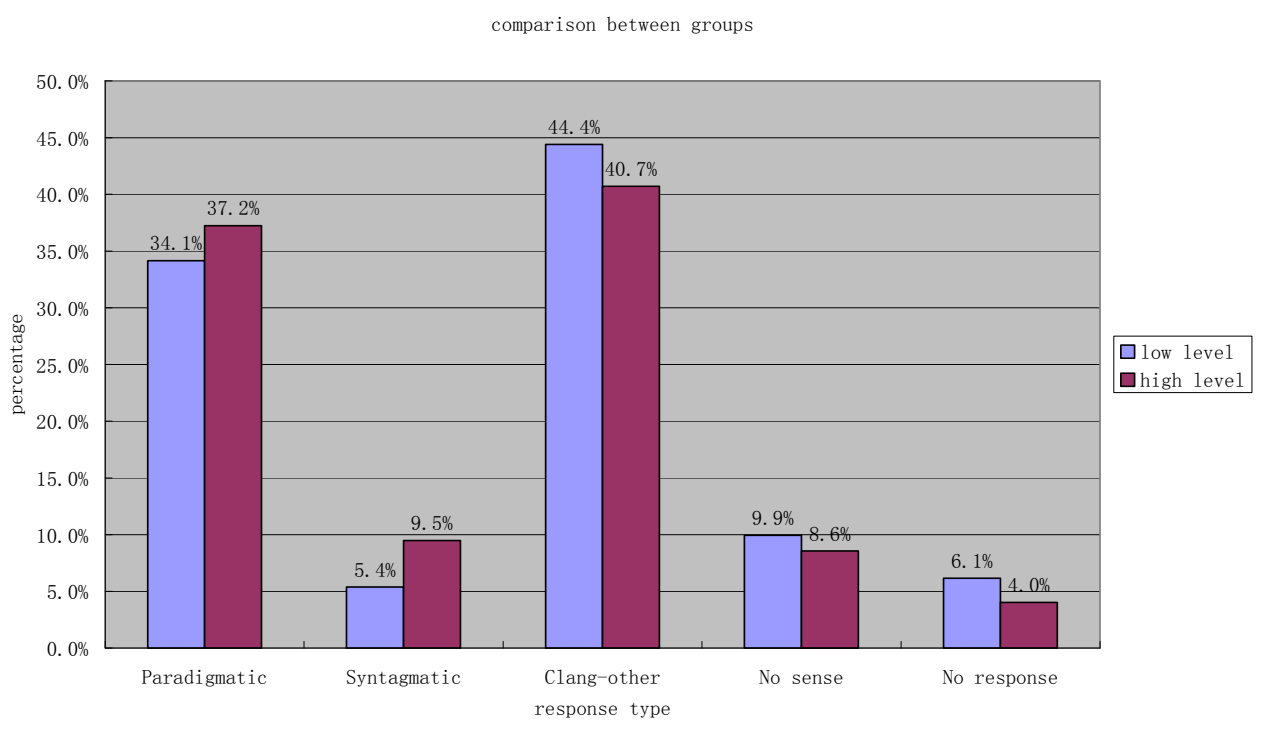

Figure 2. Response types between high level and low level groups 
As shown in Figure 2, both high and low level groups produced a highest proportion of clang-other responses and the next is paradigmatic response. High level group produced higher proportion of syntagmatic responses than no sense response while low level group produced higher proportion of no sense response than syntagmatic response. Next, the total number of each response types of each stimulus words was calculated. Then, the data was input into SPSS 19.0 and one-way ANOVA was performed to test if there is any significant difference among the five types of responses between high level and low level groups. The result is shown in the following table 4 , which indicates a significant difference generated by high and low level groups $(\mathrm{P}=0.000, \mathrm{P}=0.000$ respectively).

Table 4. One-way ANOVA of high and low level groups

\begin{tabular}{llrrrrc}
\hline Groups & & Sum of squares & df & Mean square & f & Sig. \\
\hline High level & Between type & 14158.549 & 4 & 3539.637 & 86.653 & .000 \\
& Within type & 12009.437 & 294 & 40.848 & & \\
Low level & Between type & 14988.618 & 4 & 3747.154 & 88.306 & .000 \\
& Within type & 12475.569 & 294 & 42.434 & & \\
\hline
\end{tabular}

Another ANOVA was run to show whether there is a significant difference between high level and low level groups for the number of responses across the five types. The result is shown in Table 5, which indicates statistically significant differences between two groups for syntagmatic responses $(p=0.018)$ and no responses $(\mathrm{P}=0.044)$, but there is no significant differences between two groups for paradigmatic responses $(\mathrm{P}=0.453)$, Clang-other responses $(\mathrm{P}=0.362)$ and no sense responses $(\mathrm{P}=0.348)$. The analysis proved again that the association patterns of L2 learners is a mix of semantic and phonological organization since both high level and low level groups produced similar number of semantic and phonological responses. While in spite of the closeness of response patterns, a transfer of syntagmatic to paradigmatic, meaningless responses to more meaningful responses can be seen clearly from the statistics, for the reason that high level group produced relatively higher percentage of paradigmatic responses $(37.2 \%$ vs. $34.1 \%)$ and syntagmatic responses $(9.5 \%$ vs. $5.4 \%)$ than low level group and lower percentage of clang-other responses ( $40.7 \%$ vs. $44.4 \%)$ and no responses $(4.0 \%$ vs. $6.1 \%)$.

Table 5. One-way ANOVA of Different Types of Responses between High and Low Level Groups

\begin{tabular}{llrrrrr}
\hline Response Types & & Sum of squares & df & Mean square & $\mathrm{f}$ & Sig. \\
\hline Paradigmatic & Between groups & 57.485 & 1 & 57.485 & .566 & .453 \\
& Within groups & 11885.221 & 117 & 101.583 & & \\
Syntagmatic & Between groups & 68.250 & 1 & 68.250 & 5.753 & .018 \\
& Within groups & 1388.103 & 117 & 11.864 & & \\
Clang-other & Between groups & 63.892 & 1 & 63.892 & .837 & .362 \\
& Within groups & 8932.662 & 117 & 76.348 & & \\
No sense & Between groups & 9.101 & 1 & 9.101 & .890 & .348 \\
& Within groups & 1196.882 & 117 & 10.230 & & \\
No response & Between groups & 24.278 & 1 & 24.278 & 3.797 & .044 \\
& Within groups & 748.159 & 117 & 6.395 & & \\
\hline
\end{tabular}

Similar organization patterns have also been found in some other studies. Ard and Gass (1987) claimed that "an increasing importance of semantically based factors in lexical organization as learners increase in proficiency". Cunningham (1990) found that students who have accepted more language input produced fewer clang-other responses and more paradigmatic responses. And those studies, which originally aimed at proving similar developmental route of L2 mental lexicon organization patterns, could not deny the importance of phonological patterns for even L2 learners with high proficiency. Sóderman argued that according to WA results, even the 
most advanced learners still produced large amount of syntagmatic and clang-other responses, which shall seldom occur in L1 learners. In another research, Namei admitted that clang associations occur at even the higher level group, which indicates that phonological pattern plays important role in L2 mental lexicon organization.

\subsection{Comparison between WA Responses and Result of VKS Test}

The following tables (table $6 \& 7$ ) show the percentages of response types between the two groups of subjects according to different degrees of familiarities to the stimulus words.

Table 6. Comparison between high level and low level groups for stimulus words with high familiarity

\begin{tabular}{cccc}
\hline Types & Total & low level & high level \\
\hline Paradigmatic & $46.7 \%$ & $46.3 \%$ & $47.1 \%$ \\
Syntagmatic & $10.9 \%$ & $7.7 \%$ & $14.0 \%$ \\
Clang-other & $33.4 \%$ & $34.8 \%$ & $31.9 \%$ \\
No sense & $6.9 \%$ & $8.2 \%$ & $5.5 \%$ \\
No response & $2.2 \%$ & $3.0 \%$ & $1.5 \%$ \\
\hline
\end{tabular}

Table 7. Comparison between high level and low level groups for stimulus words with low familiarity

\begin{tabular}{ccc}
\hline Total & low level & high level \\
\hline $4.6 \%$ & $3.2 \%$ & $5.9 \%$ \\
$0.6 \%$ & $0.5 \%$ & $0.7 \%$ \\
$67.7 \%$ & $69.0 \%$ & $66.4 \%$ \\
$12.2 \%$ & $10.0 \%$ & $14.3 \%$ \\
$15.0 \%$ & $17.3 \%$ & $12.7 \%$ \\
\hline
\end{tabular}

A contrast between high level and low level group still occurs with syntagmatic responses where high level group shows much higher percentage (14\%) than low level group (7.7\%). As a result, it is easy to know that L2 learners of English could produce more semantic responses when they are very familiar with the words and with the increase of language proficiency, more syntagmatic responses will occur. However, phonological effects could not be ignored even when learners are familiar with the stimulus and a shift of phonological to syntagmatic shall occur when their English ability increases.

Very low percentage of paradigmatic responses happen with this group of stimulus words and there is no significant difference between high level and low level group among types (as shown in table 4.10). The contrast between the two groups of responses happen at no sense responses where high level group appears to have more $(14.3 \%$ vs. $10 \%)$ than low level group and no responses where on the contrary low level group produced more of this type (17.3\% vs. $12.7 \%)$. The result indicates that when L2 learners are not familiar with the words they try to produce a lot of phonological responses. If the learner has rather low language ability, he or she tends to fail at producing any response. If the learner has comparatively high language ability, he or she tries to produce more meaningful responses where consequently some pseudo words, wrong collocation or random thinking may happen. It is also reasonable to predict that with the increase of his or her proficiency, more semantic responses will occur in the learner's mental lexicon pattern.

\subsection{The Most Frequent Responses}

The top three most frequent responses to each stimulus word were chosen to analyze "the degree of commonality" (Schmitt, 1998a). Since there is altogether 60 stimulus words and 88 subjects, it is too much work to analyze each response. Therefore, 30 subjects were chosen ( 10 with the highest language proficiency; 10 at the medium level; 10 with the lowest proficiency) as representation. There are altogether 60 stimulus words and 168 most frequent responses (some stimulus has only two frequent responses for the reason that there is no more response coming from more than one subject and therefore it is impossible to collocate to "the degree of commonality"). 92 out of 168 responses are clang-other responses, a surprising percentage which is not likely to happen among L1 learners. 
Among the 92 most frequent clang-other responses, 40 of which have derivative relationships with the stimulus words, such as LIFE-live; JOURNAL-journalist; VISION-visual; IDENTITY-identical; ADVENTURE - adventurous, etc. And 22 of the derivational responses associated with words of high frequency. 32 of the 92 clang-other responses are orthographical patterns of the stimulus words and 20 of them have phonological relationships with the stimulus. Examples of orthographical associations are: PRESIDENT — present; CASTLE—cast; COMMODITY — common; DEBATE—delete, etc. Phonological examples are: ELEMENT—elephant; BIAS—by; MEDIUM — media; CEASE—ease, etc. Different from phonological responses, both derivational responses and orthographical responses are form-based connections.

Of the 168 top three most frequent responses, 62 are paradigmatic responses and only 14 have syntagmatic relationships with the stimulus.

From the result, we can see that students rely a lot more on form-based connections in WA test than on sound connections. One reason for this might be the written-written form of WA test taken by the subjects. When the subjects are not very familiar with the stimulus words, it is easy for them to seek for words with similar forms from their lexicon storage. However, large proportion of derivational responses and orthographical responses can be found even with words of high familiarity such as BEAUTY - beautiful, SELL—sale/ sold, DEPRESS - press/ depression and VARIOUS - vary, etc. This is possibly due to the learning experience students get from formal classroom instruction. Nation (1990) points out that the way in which a word is taught or learned has strong impact on learners' vocabulary acquisition. When sitting in foreign language classroom, it is very common to see teachers put great emphasis on teaching words that share similar sounds and forms since it is firmly believed that it is an efficient way of expanding L2 vocabulary. As a result, overwhelming information of words that have no semantic connections stored in learners' minds and they frequently get confused to distinguish the respective meanings and spellings of similar words.

With words that learners are not familiar with, it is natural to produce clang-other responses since they have nothing to rely on but the sound and form of the word. However, for words that learners are pretty familiar with, the reason of producing rather high percentage of clang-other responses may be the weak semantic connections built in the process of achieving new words.

On the other hand, the low percentage of syntagmatic responses may due to the reason that the lexicon networks in L2 learners' mind is rather incomplete, it is very difficult for them to produce associations like that of native speakers, especially for syntagmatic responses which need specific and more syntactic knowledge of the language. Another factor that influences L2 semantic association patterns is the interruption of their own language. The cognitive process and perception of knowledge is always based on prior knowledge existed in one's memory. So it is undoubted that when learning another language, adult L2 learners will naturally rely on their memory of native language, and therefore, the L1 semantic knowledge stored in minds will transfer for the production of semantic responses. According to Kellerman (1986), L2 learners judge the type of senses by realizing the shared semantic elements with their "prototypical sense" (Kellerman, 1986) of the similar word in L1 knowledge system. "Prototypical sense" refers to words or phrases that connect with the learners' previous cognitive image or schema. Learners are "equipped with the ability to judge the degree with which an object... matches with this prototype or image". Therefore, paradigmatic knowledge is more likely to be shared than syntagmatic knowledge between two languages because the latter depends more on specific language grammatical system which shares little in common between different languages.

\subsection{Discussion}

The result for the present study indicates that the organizational pattern of L2 mental lexicon is rather a mix of semantic and non-semantic connections than a simple semantic network or phonologically dominant connections. The overall distribution of five types of responses shows that clang-other responses and paradigmatic responses share similar proportion of the total although clang-other responses have relatively higher percentage than that of paradigmatic responses. With the increase of learners' language proficiency, the difference between the two types becomes less obvious.

The frequency of words will also influence the subjects' response types. The analysis on the subjects' different response types to the stimulus words at high and low frequency levels reveals that when the subjects are more familiar with the word, they tend to produce more semantic responses. The result discovers the relationship between word acquisition and language input. Since high frequency words are introduced at the early learning stage and are frequently used in and outside classroom, abundant encounters and practice appear in all kinds of language activities. Therefore, whatever is the subjects' language proficiency, it is easier for them to produce semantic associations than to words of low frequency. 
Classroom instruction and teaching method could also have strong influence on subjects' association patterns. Existence of high proportion of derivational and morphological responses in the clang - other responses at both high and low level groups can prove this. Since L2 learners are always exposed to words of similar forms in the process of acquiring new words in classroom learning, they get used to memorize words by sounds and forms rather than meanings. It is easy for them to get input of large number of vocabulary in a short time and therefore it is considered an efficient way of teaching words. However, in the long run, the teaching method leads to disorganization of learners' mental lexicon and the learners always get confused of the meanings of words with similar forms because they could not retrieve word meanings from the appropriate entries of their lexicon storage.

Another detectable feature of the subjects' responses in the present study is misperception of stimulus words. Some unfamiliar words were misperceived as high frequency words, and therefore elicited no-sense responses or responses that have clear semantic relationships with misperceived stimulus. Those misperceived words usually share the same or similar beginnings or endings with the stimulus, such as CHIEF-chef and JOURNAL - journey. According to "bathtub effect" (Aitchison, 1987), one remembers the beginnings and endings of words better than the middle parts when memorizing new words. When people can not remember the difference in the middle parts of two words, the confusing parts merge together in their minds, and misperception happens. Concerning L2 mental lexicon, misperception happens when the subjects get confused of the stimulus with another more familiar word which shares similar beginning and/ or ending or when the subjects do not know the stimulus in their mental store. The misperception of stimulus word is a unique feature of L2 lexicon organization where words of similar forms and sounds tend to bond together and result in frequent sound-based or form-based associations.

The data for the present study shows that the network in L2 mental lexicon is still not well built even at advanced learning stage. This can be seen from the dominant clang-other responses existing at both high and low level group. And for very common words like LIFE, BEAUTY and HOPE, proportionate phonological and derivational responses were generated by learners with comparatively high language proficiency. In this case, instructors need to intentionally help learners establish efficient lexical networks within mind for better comprehension and production (Sokman, 1997). Reconstruction of the L2 mental lexicon need to involve incorporate of new meanings into the present existing mental lexicon, to reinforce of present semantic system and to reorganize of the confused links.

\section{Theoretical and Pedagogical Implications}

The ultimate purpose of the research is to shed light on L2 vocabulary acquisition and the method of English teaching. Theoretically, the findings of the present research hope to increase the adequacy of theories concerning L2 mental lexicon. It also attempts to make practical contributions to L2 pedagogy.

\subsection{Theoretical Implications}

The issue of phonological or semantic view of mental lexicon has long been existing and unsolved. One of the research questions of present study is to prove the organizational patterns of Chinese L2 mental lexicon. As a result, the research finds out that the lexicon pattern for Chinese L2 learners is neither only phonological-based as Meara (1984) stated or semantic dominant as Singleton $(1990,1999)$ depicted. For Chinese L2 learners, both paradigmatic and phonological influences play important roles in their mental lexicon network. The network is rather dynamic than static. The construction of L2 lexicon network is affected by both the process of L2 acquisition and existence of L1 system.

According to Meara, phonology plays a more important role in L2 mental lexicon than that of L1 and the semantic associations produced in L2 WA test have systematic difference from those of L1. This can be seen from the statistics of present research where phonological associations occupy the highest percentage among five response types, and the paradigmatic responses also have notable differences with those of native speakers in comparison. On the other hand, Singleton claims that semantic links will strengthen in the process of integration of words into L2 mental lexicon. This is also partially supported by the result of present research. With the increase of the subjects' language proficiency, more semantic and syntagmatic responses were produced which is due to the increase in subjects' lexical knowledge.

The research also clarifies the L2 reliance on L1 mediation when making associations. L2 mental lexicon is structurally different from that of L1 because of the influence of pre-extent L1 system. As the research shows, responses from all levels of subjects include meaningful associations which come from the shared conceptual factors of the two languages. The shared paradigmatic knowledge is beneficial in the process of acquiring new words because it is easy and quick for activation of corresponding L2 paradigmatic responses in the lexical network. Although it reduces the burden of learning new words for L2 learners, the drawback is also obvious. 
When learners rely too much on this way of acquisition, they cannot develop comprehension from the perspective of L2 language, and result in fossilization of the development of L2 semantic system. This is proved by considerable proportion of no sense responses where the responses may come from L1 equivalents, and syntagmatic responses is observably less than paradigmatic responses even for advanced learners which indicates weak bond of grammatical connections existing in L2 mental lexicon network. As Wolter (2005) points out that "the process of building syntagmatic connections between words in an L2 appears to be considerably harder than the process for building paradigmatic connections." As a result, it is very difficult for L2 learners to establish a total L1 like lexicon network.

\subsection{Pedagogical Contributions}

Vocabulary acquisition is no doubt one of the most important processes in L2 learning. No other skills such as listening, speaking, reading, and writing can be conducted without acquisition of words. However, most teachers in China are dealing with vocabulary in an unprincipled way and sometimes even ignore the teaching of vocabulary in classroom, especially at tertiary level of English learning where teachers usually put more emphasis on development of other skills and leave the input of new words for students themselves. Problems such as poverty of exposure, limited time available, little attention paid, etc. evolved in this case. Considering the significance of vocabulary and the problems facing by most Chinese students, and combing the findings of the present study and the theory of mental lexicon, some implications are proposed in the following parts:

Part 1: The reconstruction of L2 mental lexicon

The analysis of the research indicates that L2 learners need to restructure L2 mental lexicon consciously so that all words are stored in a proper way for the user to get access and retrieve. Different from native speakers who store words in word family as a whole, L2 learners frequently learn words that have morphological similarities together and could not form web-like connections, which wastes space in mental lexicon and disorders the organization of some information. Hence, the proper expansion and activation of L2 learners' mental lexicon may be one of the key factors to successful acquisition.

In regard to the weak syntactic and grammatical knowledge of L2 learners shown in this research, strengthening syntagmatic connections is one of the most important task to reconstruct L2 lexical network. Recitation and collocation exercises are practical methods for classroom oriented Chinese learners. Since learning context in formal classroom education is the major language input for most learners, the task of reciting specific selected material is an effective way to get familiar with syntagmatic relations between words. Recitation of useful formulaic expressions could also help to reinforce memorization. Collocations are language specific knowledge and are not easy to transfer across languages (Rogers, 1996). Therefore, teachers for intermediate and advanced learners should emphasize collocation exercises, especially the input of idiomatic expressions which are always confusing for L2 learners.

Another way which was proposed by Meara (1992) to reconstruct the organizational pattern of L2 learners' mental lexicon is "graph theory". Graph is used to represent connections between objects. Meara assigned his subjects association task by creating chain associations based on the first word. McCarthy (1990) asked his students to draw a graph to organize the vocabulary of a particular topic according to their own preferences. The results show that learning through graph is more efficient than through unstructured vocabulary list. This also gives indication for the edition of vocabulary list of learning material which shall coincide with the organizational pattern of mental lexicon to improve word learning.

\section{Part 2: Deepening Word Knowledge}

According to the analysis in Chapter 4, classroom instruction is part of the reason that large proportion of clang-other responses was produced. Since the semantic reconstruction of mental lexicon is significant for successful vocabulary acquisition, efforts should be made to refine and modify the learning and teaching process.

Nation (1993) proposed that knowing a word includes knowing "the meaning, the written form, the spoken form, the grammatical behavior, the collocations, the register, the associations and frequency of the word." Deepening word knowledge shall include these aspects. Teaching design shall purposely engage learners in using the language in all pragmatic, authentic, and functional ways so that learners can perform them productively and receptively.

Some classroom activities have been recommended to strengthen semantic connections between related words such as fluency activities and richness activities. Fluency activities include repeated practice such as repeated reading, recording, and rehearsed talks on the same material so that it could be used fluently. For example, 4/3/2 technique asks the learners to repeat the same material three times with 4 minutes for the first time, 3 minutes for 
the second time and 2 minutes for the third time. Recording is necessary. The process is repeated until the learner is satisfied and finally they can work in pairs to propose questions to each other about the content of the text. The method could enhance the learners' syntagmatic knowledge efficiently. Activities like extensive reading, speed-reading, continuous writing and retelling are examples of richness activities. Richness activities enhance syntagmatic and paradigmatic knowledge by increasing the density of information in mental lexicon. Fluency activities and richness activities working together can help to reorganize learners' mental lexicon in both qualitative and quantitative ways.

\section{Acknowledgements}

I would like to give my special thanks to my fellow workmates at Software School of Dalian University of Technology. They spared their time in the midst of pressing affairs to help me with data collection and analysis. I also feel thankful for the students participating in the word association test and vocabulary knowledge scale test.

Also, I would convey my wholehearted thanks to my parents, my mother-in-law and my beloved husband who have taken good care of me in time of delivering my beautiful baby and have helped me to take care of the baby all the way to spare me time and energy for writing the paper.

\section{References}

Aitchison, J. (2003). Words in the Mind: An Introduction to the Mental Lexicon (3rd ed.). Oxford: Blackwell.

Anderson, R. C. (1985). The Meaning of Words in Context. Hillsdale, New Jersey: Lawrence Erlbaum Associates.

Ard, J., \& Gass, S. (1987). Lexical constraints on syntactic acquisition. Studies in Second Language Acquisition, 9, 233-252. http://dx.doi.org/10.1017/S0272263100000498

Meara, P. (1980). Vocabulary Acquisition: A Neglected Aspect of Language Learning. Language Teaching and Linguistic Abstracts, 13, 221-246. http://dx.doi.org/10.1017/S0261444800008879

Meara, P. (1982). Word association in a foreign language: A report on the Birkbeck Vocabulary. Project Nottinghan Linguistic Circular, 11, 29-37.

Meara, P. (1984). The study of lexis in interlanguage. In A. Davies, A. Howart, \& C. Criper (Eds.), Interlanguage (pp. 225-235). Edinburgh University Press.

Meara, P. (1992). Network structures and vocabulary acquisition in a foreign language. In P. Arnaud, \& H. Bejoint (Eds.), Vocabulary and applied linguistics. London: Macmillan.

Nation, P. (1990). Teaching and Learning Vocabulary. Massachusetts: Newbury House.

Nation, P. (1993). Vocabulary Size, Growth and Use (pp. 115-134). The Bilingual Lexicon, Philadelphia: John Benjamins.

O'Gorman, E. (1996). An investigation of the mental lexicon of second language learners. Teanga: The Irish Year Book of Applied Linguistics, 16, 15-31.

Richards, J. C., Platt, J., \& Plat, H. (2000). Longman Dictionary of Language Teaching and Applied linguistics. Beijing: Foreign Language Teaching and Research Press.

Rodgers, T. S. (1969). On measuring vocabulary difficulty: An analysis of item variables in learning Russian-English vocabulary pairs. IRAL, 7, 327-343. http://dx.doi.org/10.1515/iral.1969.7.4.327

Schmitt, N. (1998). Quantifying Word Association Responses: What is Native-like? System, 26, 389-401. http://dx.doi.org/10.1016/S0346-251X(98)00019-0

Singleton, D. (1999). Exploring the Second Language Mental Lexicon (p. 178, 236). London: Cambridge University Press. http://dx.doi.org/10.1017/CBO9781139524636

Söderman, T. (1993). Word associations of foreign language learners and native speakers: The phenomenon of a shift in response type and its relevance for lexical development (pp. 157-169). Finland: Abo Akademi University, English Department Publications.

Stanovich, K. E. (2000). Toward an Interactive Compensatory Model of Individual Differences in the Development of Reading Fluency. Reading Research Quarterly, 16, 32-71. http://dx.doi.org/10.2307/747348

Treisman. (1960). Contextual Cues in Selective Listening. Experimental Psychology, 242-481.

Wolter, B. (2001). Comparing the L1 and L2 mental lexicon: A depth of individual word knowledge model. 
Studies in Second Language Acquisition, 23, 41-69. http://dx.doi.org/10.1017/S0272263101001024

Wolter, B. (2002). Assessing proficiency through word associations; is there still hope? System, 30, 315-329. http://dx.doi.org/10.1016/S0346-251X(02)00017-9

Zhang, Ping. (2009). Word Association Patterns in Chinese EFL; Learners' Mental Lexicon. Dongnan University Press.

Zhang, Shujing. (2004). The CLE Mental Lexicon: Nature and Developmental Pattern. Kaifeng: Henan University Press.

\section{Appendix}

Selection of Stimulus Words

\begin{tabular}{|c|c|c|c|}
\hline Frequency & \multicolumn{2}{|c|}{ High Frequency } & Low Frequency \\
\hline Origins & $\begin{array}{l}\text { The most frequent words } \\
\text { from Brown Corpus }\end{array}$ & $\begin{array}{l}\text { The most frequent } \\
\text { word families from } \\
\text { Academic English }\end{array}$ & The Academic Word List \\
\hline Concrete Nouns & $\begin{array}{c}\text { Life } \\
\text { President } \\
\text { Cell } \\
\text { Furniture } \\
\text { Globe }\end{array}$ & $\begin{array}{l}\text { Actor } \\
\text { Bank } \\
\text { Castle }\end{array}$ & $\begin{array}{c}\text { Commodity } \\
\text { Debate } \\
\text { Element } \\
\text { Journal }\end{array}$ \\
\hline Abstract Nouns & $\begin{array}{c}\text { Vision } \\
\text { Violence } \\
\text { Identity }\end{array}$ & $\begin{array}{c}\text { Adventure } \\
\text { Beauty } \\
\text { Fashion } \\
\text { Guilt }\end{array}$ & $\begin{array}{c}\text { Achievement } \\
\text { Bias } \\
\text { Consensus } \\
\text { Medium }\end{array}$ \\
\hline Concrete Verb & $\begin{array}{c}\text { Leave } \\
\text { Raise } \\
\text { Sell }\end{array}$ & $\begin{array}{l}\text { Attack } \\
\text { Burn } \\
\text { Claim }\end{array}$ & $\begin{array}{c}\text { Cease } \\
\text { Emerge } \\
\text { Facilitate } \\
\text { Occupy }\end{array}$ \\
\hline Abstract Verb. & $\begin{array}{l}\text { Hope } \\
\text { Exist } \\
\text { Deny }\end{array}$ & $\begin{array}{c}\text { Adopt } \\
\text { Cause } \\
\text { Determine }\end{array}$ & $\begin{array}{c}\text { Advocate } \\
\text { Depress } \\
\text { Manipulate }\end{array}$ \\
\hline Concrete Adj. & $\begin{array}{c}\text { White } \\
\text { Bitter } \\
\text { Numerous }\end{array}$ & $\begin{array}{c}\text { Bright } \\
\text { Heavy } \\
\text { Greasy } \\
\text { Transparent }\end{array}$ & \\
\hline Abstract Adj. & $\begin{array}{c}\text { Effective } \\
\text { Adequate } \\
\text { Reasonable }\end{array}$ & $\begin{array}{c}\text { Ancient } \\
\text { Chief } \\
\text { Various } \\
\text { Generous }\end{array}$ & $\begin{array}{c}\text { Arbitrary } \\
\text { Definite } \\
\text { Enormous } \\
\text { Ignorant }\end{array}$ \\
\hline
\end{tabular}

\section{Copyrights}

Copyright for this article is retained by the author(s), with first publication rights granted to the journal.

This is an open-access article distributed under the terms and conditions of the Creative Commons Attribution license (http://creativecommons.org/licenses/by/3.0/). 